\title{
Brincadeiras para interação e mobilidade
}

DOI: dx.doi.org/10.18616/nrm06

Joni Márcio de Farias

Fagner Amauri da Silva Viana

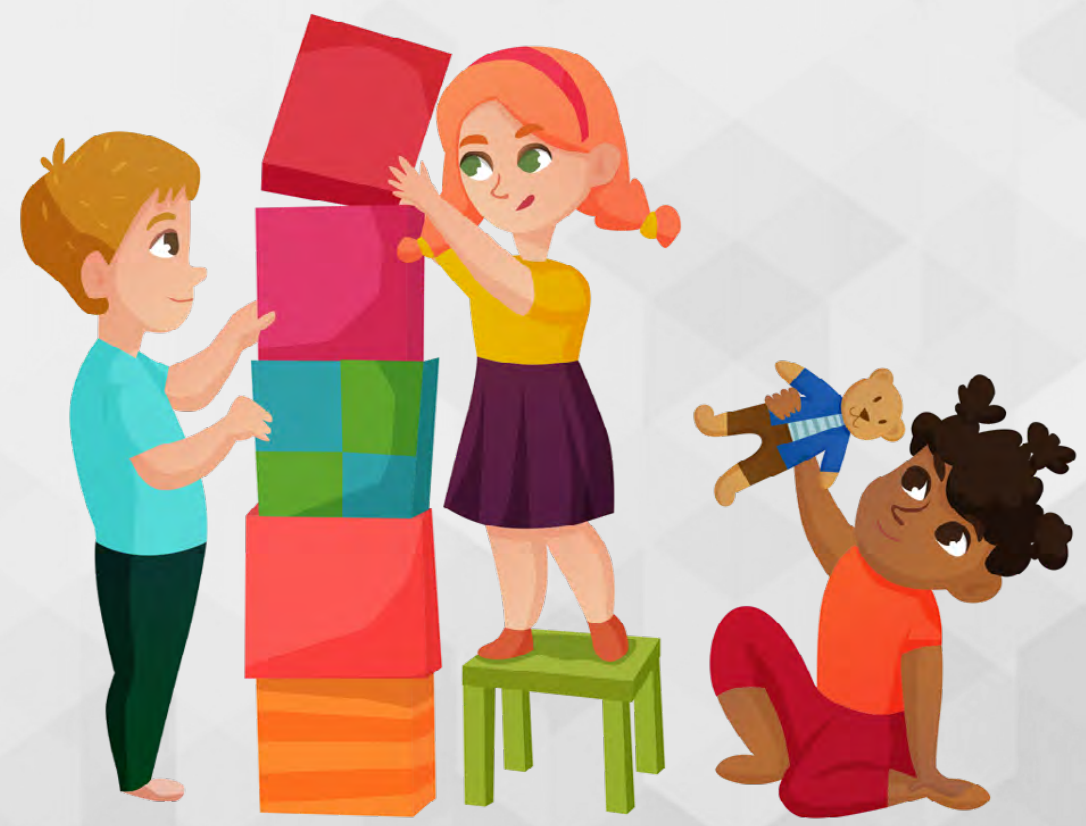


Com o tempo, muitas brincadeiras se perderam, sendo substituídas por brinquedos e pela tecnologia. O período de isolamento pode ser uma oportunidade para rememorar e praticar algumas dessas brincadeiras.

\section{A menor ilha}

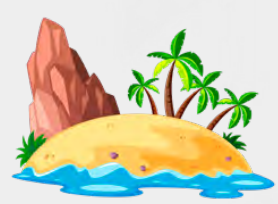

É necessário desenhar dois círculos, um dentro do outro. Os participantes receberão cinco tampinhas cada um para que sejam jogadas na tentativa de acertar o círculo menor. Para iniciar o jogo, todos deverão ficar em volta do círculo maior (sem tocar a linha demarcatória com os pés). Por ordem definida pelo comandante, e cada um na sua vez, deverão lançar a tampinha no círculo menor. O participante que colocar a tampinha dentro do círculo passará a vez para o outro. Se não conseguir acertar, jogará outra tampinha até acertar o círculo. Poderá ser limitado o número de tentativas. Vencerá quem acertar a maior quantidade de tampinhas no círculo menor. O grau de dificuldade da atividade é o tamanho dos círculos e as distâncias entre o círculo maior e o menor, podendo haver uma evolução das dificuldades de forma gradativa, ou seja, primeiro a distância entre os círculos e depois a diminuição do círculo menor.

\section{Vamos acertar no copinho}
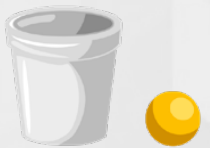

Cada participante recebe uma embalagem de iogurte e uma bolinha de tênis de mesa (podendo ser materiais alternativos como pedra, moeda, etc.). O participante que receber a bolinha iniciará a brincadeira, colocando-a dentro da embalagem. Os participantes deverão formar um círculo e, com movimento de força, fazer a bolinha saltar de sua embalagem para a embalagem do colega ao lado. Desse modo, passará a bolinha para o participante seguinte. Quem a deixar cair deverá sair da brincadeira. Poderá ser escolhido um líder ou serem realizadas algumas variações na brincadeira: se houver mais bolinhas disponíveis, a atividade poderá ser feita em duplas ou trios, utilizando a mão direita para passar a bolinha na primeira rodada, depois a mão esquerda na segunda rodada. 


\section{Roda dentro da roda}

É desenhado, no chão, um círculo de dois metros de diâmetro; e, no centro, um círculo de trinta centímetros de diâmetro. Cada participante deverá procurar pedras ou moedas para acertar o menor círculo. Cada participante ficará na extremidade do círculo maior e tentará acertar o menor. Para cada acerto poderá pegar do(a) colega o material que ele(a) terá para lançar. Ganha quem ficar com a maior quantidade de pedras ou moedas. Nessa brincadeira, podemos ter várias versões, como aumentar o maior círculo, fazer disputas individuais ou em duplas, etc.

\section{Quente e frio}

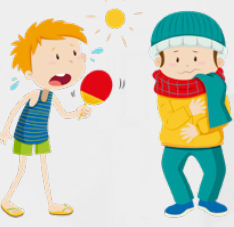

O grupo escolhe alguém para ser o líder da brincadeira. O escolhido irá esconder o lápis (ou outro objeto) em algum lugar. O restante do grupo irá procurar esse objeto. Quando estiver perto dele, o líder poderá falar em voz alta: "quente". Quando estiver longe do objeto, poderá falar: "frio”. Quem o encontrar primeiro será o líder na próxima rodada.

\section{Segure o palito}

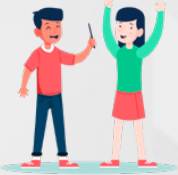

Todos os participantes deverão se sentar no chão para formar um círculo. Um dos participantes começará a brincadeira com o pauzinho na mão. Virará para seu colega da direita e começará o jogo, entregando o pauzinho e dizendo uma palavra: maçã, por exemplo. Quando seu colega receber o pauzinho e entregá-lo ao próximo, deverá entregar o pauzinho, repetir a palavra e acrescentar outra ("maçã, banana”, por exemplo), e assim sucessivamente, até que alguém complete a rodada.

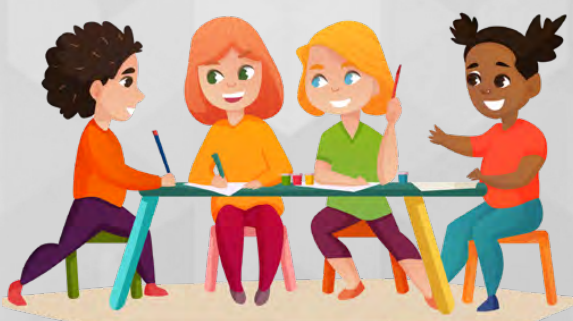




\section{Virando o gamelão}

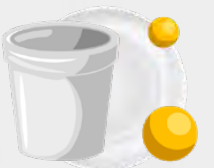

Cada participante possuirá um prato plástico e uma bolinha de tênis de mesa (podendo ser materiais alternativos), mas o prato deverá ficar com suas bordas para cima. Será estabelecida uma distância de acordo com a idade dos participantes, e cada participante terá a chance de lançar a bolinha para acertar as bordas do prato. Quem acertar o prato terá a chance de lançar novamente, e quem conseguir virar o prato para baixo poderá tirar um colega da brincadeira. Ganhará quem ficar por último.

\section{BRINCADEIRAS CANTADAS}

\section{Escravos de Jó}

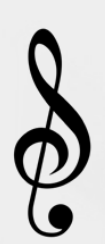

Escravos de Jó jogavam caxangá

Tira, bota, deixa ficar

Guerreiros com guerreiros fazem zigue-zigue-zá

Escravos de Jó jogavam caxangá

Tira, bota, deixa ficar

Guerreiros com guerreiros fazem zigue-zigue-zá

\section{Escute a Música}

A execução dessa música pode ser realizada em um círculo, com os participantes sentados, cada um segurando um objeto qualquer. Pode ser uma borracha, por exemplo. Ao cantarem, os participantes vão passando o objeto para o colega ao lado, no círculo. Quando chegarem à frase "tira, bota, deixa ficar", deverão retirar o objeto do círculo quando cantarem a palavra "tira" e recolocá-lo no círculo quando for a palavra "bota". Na parte em que falam "fazem zigue-zigue-zá", não passarão o objeto para o colega, apenas o colocarão na frente dele e pegarão de volta. 


\section{Terezinha de Jesus}
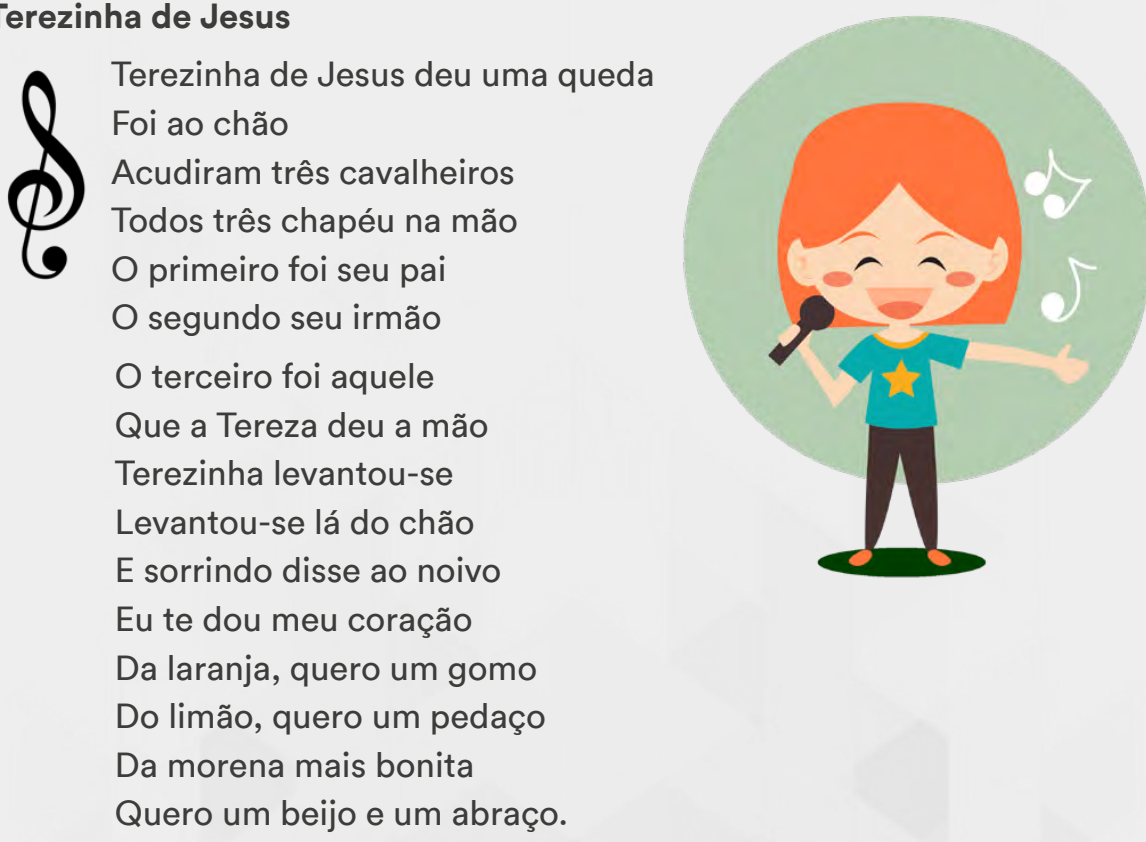

\section{Escute a Música}

Para realizar a atividade cantada, uma criança é escolhida para ficar no centro de um círculo formado por várias crianças. Ao concluir a canção, a criança que estava no meio escolhe um(a) colega para abraçar, o(a) qual a substituirá no centro da roda.

\section{Caranguejo peixe é}
$\oint$
Caranguejo não é peixe,
Caranguejo peixe é;
Caranguejo só é peixe
$\mathrm{Na}$ enchente da maré.
Ora, palma, palma, palma!
Ora, pé, pé, pé!
Ora, roda, roda, roda,
Caranguejo peixe é!
Escute a Música 
Os participantes deverão cantar a canção enquanto andam de lado, como os caranguejos. Cada vez que a música é cantada até o final, cada caranguejo deverá encontrar um par, que vai continuar andando de lado com ele, de braço dado. Se alguém não conseguir um par, ou se alguém se juntar ao número errado, sairá da roda e apenas ficará cantando para os colegas encontrarem um par. O comandante poderá ajudar falando o número de colegas que deverão dar os braços.

\section{Fui ao mercado}

Fui ao mercado comprar café

Veio a formiguinha e subiu no meu pé

Eu sacudi, sacudi, sacudi

Mas a formiguinha não parava de subir

Fui ao mercado comprar batata roxa

Veio a formiguinha e subiu na minha coxa

Eu sacudi, sacudi, sacudi

Mas a formiguinha não parava de subir

Fui ao mercado comprar melão

E a formiguinha subiu na minha mão

Eu sacudi, sacudi, sacudi

Mas a formiguinha não parava de subir

Fui ao mercado comprar jerimum

E a formiguinha subiu no meu bumbum

Eu sacudi, sacudi, sacudi

Mas a formiguinha não parava de subir

Fui ao mercado comprar um giz

Veio a formiguinha e subiu no meu nariz

Eu sacudi, sacudi, sacudi

Mas a formiguinha não parava de subir.

\section{Escute a Música}


Essa cantiga trabalha o reconhecimento das partes do corpo. Cada vez que uma parte do corpo é mencionada, o participante deverá tocá-la com sua mão.

Outras sugestões

Brilha, brilha estrelinha

Escute a Música

Cabeça, ombro, joelho e pé

Escute a Música

Dona Aranha

Escute a Música

Quem está feliz bate palmas

Escute a Música

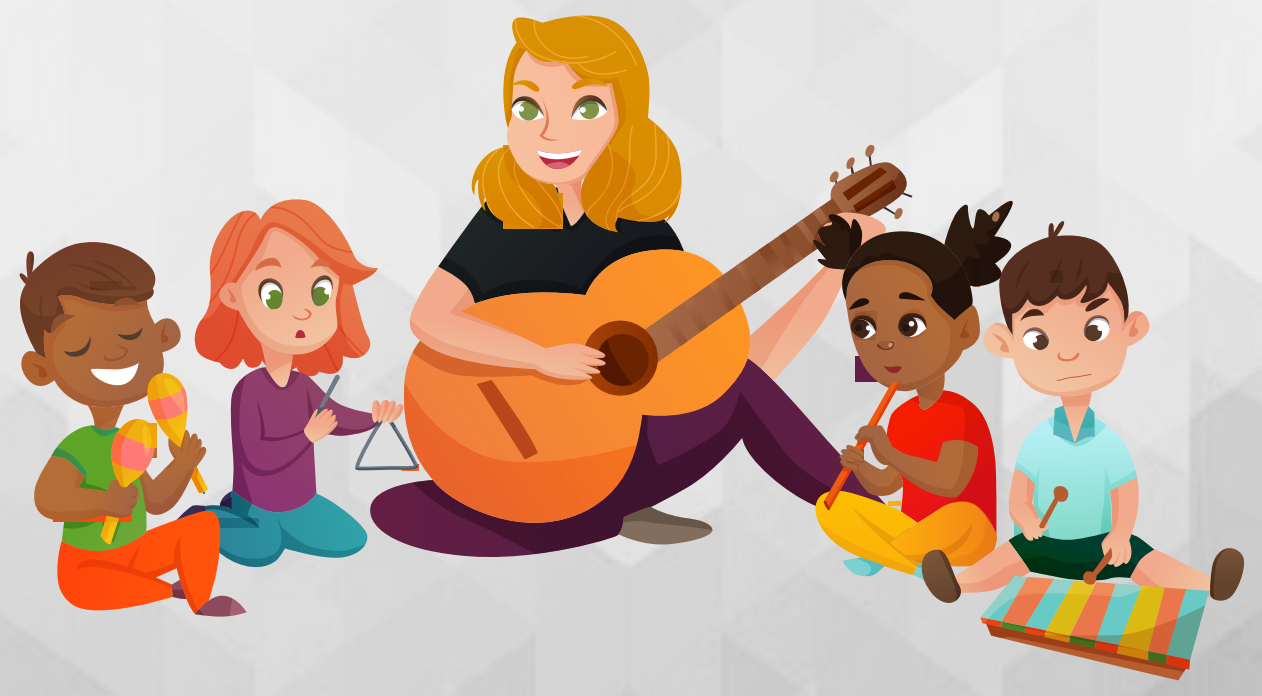

